\title{
A breakdown in institutional communication to detect and treat ADHD: case report
}

\begin{abstract}
We present the case of two children of 7 and 8years old, who have been referred from teachers and school counsellors for evaluation by health professionals, on suspicion of presenting a clinical feature of ADHD. Although this diagnosis has been repeatedly dismissed, the educational institution continues tackling the behavioural problems under this label, making constant petitions of assessment to the health system. The need for generating communication channels between the institutions in charge of the management of children with behavioural problems is discussed with the aim of avoiding cost overruns in the health system and reducing the psychosocial impact of the stigma associated with the diagnosis of ADHD
\end{abstract}

Volume 9 Issue 3 - 2019

\author{
Ángela María Vargas Rodríguez,' Sofía \\ Margarita Vinasco Molina ${ }^{2}$ \\ 'Department of psychology, National University of Colombia, \\ Colombia \\ ${ }^{2}$ Incca University of Colombia, Colombia
}

Correspondence: Ángela María Vargas Rodríguez, Department of psychology, National University of Colombia, Colombia, Tel +573044080718, Email amvargasro@unal.edu.co

Received: June 09, 2019 | Published: June 14, 2019

\section{Introduction}

It is now well established that ADHD is possibly the most diagnosed childhood-onset disorder in the world, with a global prevalence reported by the DSM-5 of $5.29 \%$, but it could be higher in some geographical areas. In this regard, several studies show prevalence ranging from $1.24 \%^{1}$ in some regions of the world, up to $20,5 \%$ at others. According to some authors, these differences could be explained by the methodological diversity of researching in this field. ${ }^{3}$ Some meta-analyses carried out in recent decades show more homogeneous data, which have been an important input to know the current state of the disorder from the epidemiological perspective. Table 1 shows data on the prevalence grouped according to some of these works.

Table I Prevalence data grouped according to meta-analysis type studies in different regions of the world

\begin{tabular}{ll}
\hline Region & Prevalence $\%$ \\
\hline Iran & $8 \%^{4}$ \\
Spain & $6,8 \%^{5}$ \\
USA & $8,4 \%^{6}$ \\
Worldwide & $3,4 \%^{7}$ \\
\hline
\end{tabular}

This panorama shows that ADHD is a health issue with significant relevance in the world because not only affects the quality and life prospects of those who suffer it but also it is a socioeconomic challenge in terms of the high costs involved in its administration. ${ }^{8}$

For this reason, it is important to discuss the role of institutions implicated in the detection of ADHD and the accuracy of the criteria in which those who do, which may decrease the socio-economic impact of that "false positives" into the system of health.

The cases presented below correspond to two school children, who have been nominated by the educational institution to which they belong to be included in the research on social aspects of ADHD. According to this, the cases have been built on the basis of the available medical records and information collected through semistructured interviews with parents and school counsellor.

\section{Case I}

A seven-year-old boy at the time of data collection. He has been referred for assessment by the EPS (Health Promoting Entity by its initials in Spanish) for presenting difficulties in the classroom, which are summarised in: the difficulty to stay in the workplace, trouble with ending activities and, aggressiveness. For the same reason, he has received 6 sessions of occupational therapy provided by the EPS the previous year and complementary sessions through a foundation.

The following results of the last of three evaluations are reported in the health history: lack of necessary skills for the functional execution of the school role due mainly to the difficulty in manual dynamic coordination, postural control, motor planning, inhibitory brake, integration and follow-up visual, location in space and difficulties in channelling visual and proprioceptive stimuli.

According to this, it is confirmed that the diagnosis refers to the occupational difficulties that interfere with the development of school learning and the presence of a clinical condition of ADHD is dismissed. An annotation of low tolerance to frustration is included that triggers episodes of aggression and tasks related to the rearing patterns and the identification of aggression triggers are advised.

After submitting a clinical report to the educational institution, the area of school counselling have ratified the presence of ADHD with predominance hyperactive-impulsive and have demanded parents to ask for the administration of pharmacological therapy by the EPS, because the occupational therapy has not given the results with the speed that is required. Therefore, until the results are not met, the decision taken has been to exclude the child from the morning classes.

\section{Case 2}

An eight-year-old boy at the time of data collection. He has been referred to the EPS for assessment due to suspected ADHD symptoms. The teacher has reported that the boy has difficulties to maintain the attention and had has episodes of excessive movements that have interrupted the development of the class. During the previous medical evaluations, the presence of a clinical condition of ADHD has been ruled out. The medical record has included a medical diagnosis of cutaneous mastocytosis $(\mathrm{CM})$ which, according to the mother of the 
child, it has been associated with a problem of attention and events of excessive movement due to the itching sensation on the skin.

Despite this diagnosis is known by the educational institution, the school has exerted pressure on the mother to request form the EPS another assessment by psychiatry or psychology. During the assessment has been determined that the child has an average IQ, with attention difficulties. Therefore, a diagnosis of attention deficit, without fulfilling all the criteria for a clinical feature of ADHD has given. Consequently, the child has been referred to occupational therapy.

As in the previous case, the educational institution has requested therapeutic alternatives that get results in less time and has insisted that the child has ADHD with a predominance of hyperactivity. The mother has been threatened by the school with the no admission of the child at the school for the following year.

\section{Discussion}

Consistent with the data shown in the introduction, ADHD has been a very important disorder due to its high prevalence and the tendency to increase the number of new cases yearly, according to research on its incidence. ${ }^{9-12}$ However, systematic studies have shown that the methodologies used to calculate this data could result in excessively high rates regarding the presence of the disorder within the child population, which represents a challenge in terms of unifying and clarifying the criteria under which diagnosis has been done.

The panorama that lives every day the institutions in charge of detecting, reporting and treating disorders such as ADHD, has not been alien to these methodological techniques, especially the schools, which through the teachers have reported and referred the children with behavioural difficulties to specialised health centres. Thus, in Colombia, the care route has begun in the classroom, where the child has been sent to the school counselling area and from there to the health service provider institution, usually financed by the State. ${ }^{13}$

The initial role of the teacher in the detection of symptoms of ADHD is practically universal, so several researchers have been interested in exploring the biases that affect the judgment of teachers during this task, finding that this has been affected by variables such as gender and the expression of symptoms. In this sense, teachers have reported more often to boys than to girls, especially those who show symptoms of hyperactivity-impulsivity, or the combined subtype, with the idea that pharmacological treatment is more beneficial for these subtypes than for inattentiveness. ${ }^{14,15}$

The generalised idea that children are more prone to hyperactivity can generate a particular sensitivity of teachers to pay more attention to disruptive behaviour in the classroom by their male students, ${ }^{16}$ and therefore a greater willingness to refer them to specialised services. In spite of this fact has served to argue a possible under diagnosis in girls, ${ }^{17}$ it should also be a reason to reflect on the possibility of over diagnosis in children, taking into account that the report of the teachers about the presence and the severity of the symptoms is decisive when it comes to diagnosing ADHD.

On the other hand, the authors have called attention to some difficulties at the time of diagnosing ADHD that can lead to the generation of "false positives". Firstly, there is the fact that the assessment has not included an objective test and rather it has been based on reports of caregivers and teachers with a high dose of subjectivity. Secondly, the fact that there is more than one diagnostic manual with different criteria and rules that also have a wide range of interpretation and behaviours that can also occur in children without ADHD. ${ }^{18,19}$

Different studies have shown the impact of the diagnosis of ADHD both personally and socially and within this context, false positives achieve great importance. In regards to psychosocial consequences, it has been found that having the diagnosis can generate expectations among parents and teachers of academic performance ${ }^{20}$ such as negative emotions and the lower degree of confidence with the child. ${ }^{21}$ In addition, the psychosocial functioning has been worsened of people whose symptoms have remained until adulthood in terms of labour, economy, and family. ${ }^{22}$ ADHD also has had a socioeconomic impact derived from the costs of its assessment and treatment to the health system, as it has been reported in several countries. ${ }^{8,23-25}$

In the same way, the control of false positives would have a favourable impact on both the reduction of the stigma associated with the diagnosis and the reduction of over-claims to the health system. In this regard, although it is true that the costs derived from the treatment depend to a great extent on the reliability of the diagnosis made by the health professionals, this is not always the case when concerns to the costs due to the assessment.

This can be observed in the cases presented, where the educational institution asked constantly to the health system trying to verify that behavioural problems responded to a feature of ADHD, even after the disorder was dismissed, which have generated both cost overruns in the health system and, emotional consequences for children and their families.

Both cases represent the gap between two central institutions in the management of ADHD that must work together. In that sense, a constant demand of the teaching staff of the schools has been the intervention of health professionals, not only in regards with the affected student but also about to the increase of the capacity for detecting with reliability the signs of the ADHD, as well as generate fitted strategies for each case ${ }^{13}$ all of them through a suitable training.

\section{Conclusion}

To achieve this aim it is necessary to generate communication channels between both institutions, which would address at least two urgent issues in regards to the management of ADHD at schools: improving the competencies of the teaching staff in the detection and management of symptoms of ADHD, both clinical and subclinical, in order to strength the capacities of the affected children; and collaborate with the construction of strategies for reducing stigma and its psychosocial consequences.

\section{Acknowledgments}

None.

\section{Conflicts of interest}

The authors of this manuscript declare that they have no conflicts of interest.

\section{Informed consent}

Informed consent was obtained from the parents of the children whose cases are reported in this document, as well as informed consent from the children. 


\section{References}

1. Wang SY, Lee SS, Yuan CJ, et al. Prevalence rates of youths diagnosed with and medicated for ADHD in a nationwide survey in Taiwan from 2000 to 2011. Epidemiol Psychiatr Sci. 2017;26(6):624-634.

2. Aboul-Ata M, Amin A. The Prevalence of ADHD in Fayoum City (Egypt) Among School-Age Children: Depending on a DSM-5-Based Rating Scale. J Atten Disord. 2018;22(2):127-133.

3. Polanczyk GV, Willcutt EG, Salum GA, et al. ADHD prevalence estimates across three decades: an updated systematic review and meta-regression analysis. Int J Epidemiol. 2014;43(2):434-442.

4. Arjmandi S, Akikhavandi S, Sayehmiri K. Prevalence of attention deficit hyperactivity disorder among primary school children according to teachers and parents' report: Systematic review and meta-analysis study. Journal of Fundamentals of Mental Health. 2015;17(5):213-221.

5. Catalá-López F, Peiró S, Ridao M, et al. Prevalence of attention deficit hyperactivity disorder among children and adolescents in Spain: a systematic review and meta-analysis of epidemiological studies. $B M C$ Psychiatry. 2012;12(168):1-13.

6. Pastor PN, Reuben CA. Diagnosed attention deficit hyperactivity disorder and learning disability: United States, 2004-2006. National Center for Health Statistics. Vital Health Stat. 2008;10(237):1-23.

7. Polanczyk GV, Salum GA, Sugaya LS, et al. Annual Research Review: A meta-analysis of the worldwide prevalence of mental disorders in children and adolescents. J Child Psychol Psychiatry. 2015;56(3):345-365.

8. Le HH, Hodgkins P, Postma MJ, el al. Economic impact of childhood/ adolescent ADHD in a European setting: the Netherlands as a reference case. Eur Child Adolesc Psychiatry. 2014;23(7):587-598.

9. Chien IC, Lin CH, Chou YJ, et al. Prevalence, incidence, and stimulan use of attention-deficit hyperactivity disorder in Taiwan, 1996-2005: a national population-based study. Soc Psychiatry Psychiatr Epidemiol. 2012;47(12):1885-1890

10. Holden SE, Jenkins-Jones S, Poole CD, et al. The prevalence and incidence, resource use and financial costs of treating people with attention deficit/hyperactivity disorder (ADHD) in the United Kingdom (1998 to 2010). Child Adolesc Psychiatry Ment Health. 2013;7(34):1-27.

11. Štuhec1 M, Švab V, Locatelli I. Prevalence and incidence of attentiondeficit/hyperactivity disorder in Slovenian children and adolescents: a database study from a national perspective. Croat Med J. 2015;56(2):159165 .

12. Vasiliadis HM, Diallo FB, Rochette L, et al. Temporal Trends in the Prevalence and Incidence of Diagnosed ADHD in Children and Young Adults between 1999 and 2012 in Canada: A Data Linkage Study. Can J Psychiatry. 2017;62(12):818-826.

13. Vargas AM, Parales CJ. La construcción social de la hiperactividad. Revista Colombiana de Psicología. 2017;26(2):245-262.

14. Coles EK, Slavec J, Bernstein M. Exploring the Gender Gap in Referrals for Children With ADHD and Other Disruptive Behavior Disorders. Journal of Attention Disorders. 2012;16(2):101-108.

15. Moldavsky M, Groenewald C, Owen V, et al. Teachers' recognition of children with ADHD: role of subtype and gender. Child and Adolescent Mental Health. 2013;18(1):18-23.

16. Isaksson J, Ruchkin V, Lindblad F. Unseen and Stressed? Gender Differences in Parent and Teacher Ratings of ADHD Symptoms and Associations with Perceived Stress in Children with ADHD. J Atten Disord. 2016:1-5.

17. Rucklidge, JJ. Gender differences in ADHD: Implications for psychosocial treatments. Expert Rev Neurotherapeutics. 2008;8(4):643-655.

18. Timimi S. The McDonaldization of childhood: Children's mental health in neo-liberal market cultures. Transcult Psychiatry. 2010;47(5):686706

19. Tizón JL. El "niño hiperactivo" como síntoma de una situación profesional y social: Mito, realidad, medicalización?. Revista de Psicopatología y Salud Mental de Niño. 2007;2:23-30.

20. Eisenberg D, Schneider H. Perceptions of Academic Skills of Children Diagnosed With ADHD. J Atten Disord. 2007;10(4):390-397.

21. Ohan JL, Visser TAW, Strain MC, et al. Teachers' and education students' perceptions of and reactions to children with and without the diagnostic label “ADHD”. J Sch Psychol. 2011;49(1):81-105.

22. Franke B, Michelini G, Asherson P, et al. Live fast, die young? A review on the developmental trajectories of ADHD across the lifespan. Eur Neuropsychopharmacol. 2018;28(10):1059-1088.

23. Sciberras E, Lucas N, Efron D, et al. Health Care Costs Associated With Parent-Reported ADHD: A Longitudinal Australian Population-Based Study. J Atten Disord. 2013;21(13):1063-1072.

24. Guo L, Danielson M, Cogan L, et al. Treatment Patterns and Costs Among Children Aged 2 to 17 Years With ADHD in New York State Medicaid in 2013. J Atten Disord. 2018;1087054718816176.

25. Libutzkia B, Ludwiga S, May M, et al. Direct medical costs of ADHD and its comorbid conditions on basis of a claims data analysis. Eur Psychiatry. 2019;58:38-44. 